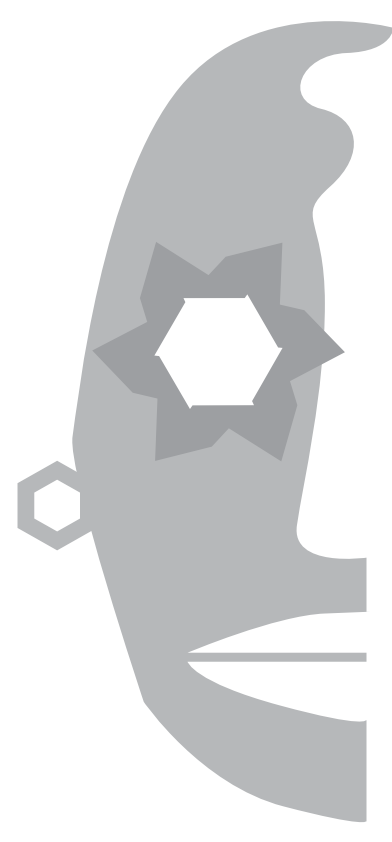

Elena Oliva

Universidad de Chile.

Becaria CONICYT

\section{Blas Jiménez y Quince Duncan: dilemas del escritor afrohispano}

\section{Resumen}

El artículo presenta una reflexión sobre la categoría 'escritor afrohispano' y las tensiones que involucra. En la primera parte se discute sobre el surgimiento, las utilizaciones y apropiaciones que intelectuales afrodescendientes han hecho de este concepto desde fines de los años ochenta. En la segunda parte se analiza el principal dilema de estos escritores en torno a las posibilidaddes de expresar una identidad específica, la de los afrodescendientes en la América de habla hispana, desde la lengua del colonizador, a través de las reflexiones y propuestas contenidas en la producción ensayística del poeta dominicano Blas Jiménez y del narrador costarricense Quince Duncan.

Palabras clave: escritor afrohispano; intelectuales afrodescendientes; Blas Jiménez; Quince Duncan.

\section{Abstract}

This article is a reflection on the category of Afro-Hispanic writers and the tensions it provokes. The first part of the article discusses the origins, uses, and appropriations of this concept made by intellectuals of African descent since the late 1980s. The second part analyzes the Afro-Hispanic writer's chief dilemma of using the colonizer's language to express a specific identity, that of Afro-descendants in Hispanic America. This discussion draws on the reflections and proposals outlined in the essays by Dominican poet Blas Jimenez and Costa Rican narrator Quince Duncan.

Keywords: Afro-Hispanic writer, Afro-descendant intellectuals, Blas Jimenez, Quince Duncan 
La categoría 'escritor afrohispano' es una clasificación interesante para reflexionar sobre los procesos creativos de una América Latina heterogénea. Por un lado, esta denominación alude a un rol productivo dentro del campo intelectual, el de escritor; por otro lado, con el prefijo afro reconoce un lugar de enunciación específico (racializado dirán algunos, diaspórico sostendrán otros); y finalmente, asume una determinada herencia lingüística y cultural, la hispana. La relación entre estos aspectos no es fácil, y no solo por el hecho de que cada uno de ellos nos abre a una discusión específica que tiene su trayectoria propia, sino sobre todo porque en el cruce de estas categorías surgen varias problemáticas -el racismo activo en el campo intelectual latinoamericano, el largo proceso de identificación como afrodescendientes en el contexto de la América Latina hispana, la tensión lingüística que implica asumir la lengua del colonizador, entre otras-, lo que nos indica que estamos ante una figura difícil de encasillar, pero clave para comprender el desarrollo de la intelectualidad afrodescendiente en la región.

Blas Jiménez, poeta y ensayista de República Dominicana, y Quince Duncan, narrador y ensayista de Costa Rica, son dos intelectuales que han sido catalogados en innumerables investigaciones como escritores afrohispanos. Ambos, en la autoría y en sus propuestas literarias, se reconocen como afrodescendientes y desde ese espacio han problematizado el proceso creativo del escritor, en el que la lengua tiene un lugar determinante como articuladora de una identidad y de una memoria que constantemente están en disputa con la cultura hegemónica de la América Latina de habla hispana. Así, mientras Jiménez apunta al rol del escritor afrodescendiente en la zona de habla española, Duncan se enfoca en una propuesta literaria -el afrorrealismo. El propósito de este artículo es poner en diálogo sus propuestas y discutirlas en torno a las posibilidades que involucra lo afrohispano.

\section{Literaturas y autorías afrohispanas}

Difícil resulta precisar cuándo apareció por primera vez la categoría 'afrohispano', pero en el ámbito de la literatura todo parece indicar que fue en los años ochenta cuando esta denominación cobró fuerza de la mano del crítico estadounidense Richard Jackson (1988), quien la utilizó para referirse a autores afrodescendientes en la zona hispanohablante del continente' ${ }^{1}$. Según Jackson, la producción escrita de afrodescendientes en la América hispana se puede rastrear desde comienzos del siglo XIX - propuesta contenida en su libro de 1979-, pero es particularmente en la segunda mitad del siglo XX, a partir de los años setenta y ochenta, cuando se

1 También, en 1988, Edward Mullen publicó “The Emergence of Afro-Hispanic Poetry: Some Notes on Canon Formation", un ensayo que se enfoca en el trabajo poético. Mullen, al igual que Jackson, no profundizó en lo que implica esta clasificación, aunque resulta evidente que ambos la han empleado para dar cuenta de autores afrodescendientes y sus producciones literarias que se circunscriben a la América de habla hispana. 
observa no sólo un interés creciente de la crítica por indagar en sus producciones y explorar nuevas áreas de investigación, como el estudio de las representaciones de la mujer negra, sino además un aumento en las publicaciones de autores afrodescendientes, la introducción de nuevos formatos como el teatro y la aparición de nuevas autorías como las escritoras afrohispanas.

Según Jackson, este fenómeno se vincula al afrocentrismo, una perspectiva que aunque no la explica mayormente, enfatiza la condición diaspórica de los afrodescendientes, recogiendo el legado africano traído por los esclavizados y a su vez complementándolo con la experiencia de sus descendientes en América. Este enfoque, se puede agregar, no sólo busca visibilizar la presencia del sujeto afrodescendiente, motivación que viene desde mucho antes de este período, sino cuestionar cómo ha sido comprendida esa presencia, pues parte de la base de que los descendientes de africanos y africanas están en los orígenes de la construcción de las sociedades latinoamericanas, y lo que persigue es volver a mirar esa historia desde su punto de vista. En el plano literario, la perspectiva afrocéntrica apuesta por una voz más agresiva, que se interesa por tratar temáticas propias y sobre todo porque demanda abrir el canon a una nueva forma de crear.

La literatura y autorías afrohispanas emergen, por un lado, de un conocimiento largamente acumulado, que Jackson denomina experiencia negra; y, por otro, de un contexto que facilita su desarrollo. Esta hipótesis, que sostiene a partir de declaraciones y observaciones hechas por los mismos escritores afrodescendientes en sus publicaciones, no está exenta de algunas dificultades. El crítico estadounidense entiende la experiencia negra como el desarrollo de una autoconciencia de ser negro, que desde los tiempos de la esclavitud se ha ido acumulando en un proceso continuo y creciente. Esto habría permitido dar paso a una literatura de estética negra, o dicho de otra manera, a representaciones y autorías auténticas. De este modo, Jackson genera un vínculo entre la experiencia, la conciencia de una negritud y la autoría, lo que resulta problemático, pues supone no sólo la homogeneidad de un grupo -los negros- que en sí es muy diverso, sino que asume la preexistencia de la raza negra, sin cuestionar las construcciones sociales, culturales y poder que en torno a esta categoría se han desplegado históricamente ${ }^{2}$.

Respecto al contexto, Jackson hace referencia al impacto que los movimientos negros de Estados Unidos habrían tenido en América Latina durante los años setenta. Aunque no se puede obviar la evidente influencia de estos sucesos, el autor no considera otras situaciones igualmente relevantes para comprender los procesos intelectuales de los afrodescendientes en este período, algunas externas a América Latina, como la descolonización e independencia de una buena parte

2 Silvia Valero observa las dificultades de este concepto para el caso colombiano (2013). 
de los países de África, y otras internas, como la descolonización e independencia del Caribe inglés, que sin duda aportaron a configurar un momento triunfalista para los afrodescendientes en la diáspora. A ello se suma que tampoco toma en cuenta una etapa de importantes transformaciones en América Latina, que entre los años cincuenta y setenta incluyó los procesos revolucionarios y el giro hacia un contexto general de represión. A causa de lo anterior, en algunos países fue de la mano de golpes de Estado de corte fascista con participación militar y civil. El viraje hacia ese momento de opresión en la historia latinoamericana desarticuló las diversas formas de organización de la sociedad y puso fin a procesos de democratización política y social que también habían alcanzado a los afrodescendientes (Andrews, 2007). Cabe mencionar aquí que los altos niveles de movilidad e integración social que lograron fueron de la mano con el debilitamiento de su identidad específica -la de negros- que le había dado forma a su organización social, política y cultural durante las primeras décadas del siglo XX, pero que alrededor de los años sesenta tendió a subsumirse en los enfoques de clase que fueron hegemónicos en la región, difuminándose sus particularidades en los interses sectoriales de las clases medias y populares.

Al observar más de cerca el telón de fondo de la emergencia de la literatura afrohispana en los años setenta y ochenta, es posible proponer que el afrocentrismo es un enfoque que entregó a los afrodescendientes la posibilidad de volver a vincularse desde otro lugar luego de estos quiebres, tomando distancia -mas no desligándose por completo de ellas- tanto de perspectivas negristas ${ }^{3}$ que exaltan la opresión racial, como de perspectivas de clase que someten sus particularidades a una categoría más abarcadora, para enfatizar ahora el proceso diaspórico del que son herederos.

De esa manera, es necesario comprender la categoría 'afrohispano' como una denominación externa al campo intelectual latinoamericano, pero que ha sido aceptada y en algunos casos adoptada para sí por escritores e intelectuales afrodescendientes. Han sido justamente ellos quienes la han contextualizado y problematizado políticamente, capturando las tensiones históricas y culturales que implica el término para transformarlas en un desafío. Manuel Zapata Olivella, escritor colombiano y uno de los intelectuales afrodescendientes más relevantes dentro del ámbito hispano, señaló (2006) que los escritores afro-latinoamericanos han debido enfrentarse a una serie de obstáculos para desarrollar su literatura: el mestizaje que, como ideal de la nación latinoamericana, intentaba hacer frente a una diversidad cultural considerada como conflictiva y amenazante; la identidad nacional que, al ser pretendidamente hispánica, borró a indígenas y

3 Con este concepto no me refiero al negrismo, sino a la perspectiva que se articula desde el reconocimiento de una identidad negra. 
afrodescendientes, invisibilizando su presencia e impidiendo el desarrollo de una literatura propia; asimismo, la opresión cultural que subestima sus aportes, los margina del acceso a la educación y les oculta su propia historia. Siguiendo esta senda, Carlos Guillermo Wilson, escritor afropanameño, en un breve texto pero con sugerente título ("El rol del escritor afro-latino y el quinto centenario", 1991), también se cuestiona sobre los desafíos del escritor afrodescendiente, destacando tres nudos temáticos: la identidad y el problema de la invisibilización del afro, la justicia y la lucha contra la discriminación racial, y la conciencia cultural, que pone en relación con la responsabilidad de este escritor por transmitir las herencias africanas en América.

La reflexión que proponen ambos autores, brevemente esbozada, contrasta con la de Jackson, no sólo porque se desprende de, y se vincula a, los procesos latinoamericanos, sino sobre todo porque evidencia las diversas y profundas variables que han impedido el desarrollo pleno de la literatura afrohispana, la que en ningún caso estaría gatillada únicamente por procesos externos. Zapata Olivella y Wilson, más que poner el foco en la emergencia de la literatura afrohispana, demandan su despliegue, y es justamente sobre esta acción creadora de lo que Jiménez y Duncan se van a hacer cargo más tarde.

\section{Jiménez, Duncan y la lengua subversiva}

Quince Duncan y Blas Jiménez irrumpieron en la escena pública de sus países durante la década de los setenta y ochenta, respectivamente, cuando el primero publicó su libro de cuentos El pozo y una carta en 1969, y Jiménez una década más tarde lo hizo con su poemario Aquí...otro español, en 1980, generando ambos, al menos, desconcierto. Costa Rica, República Dominicana, y en general todos los países de la América Latina hispana, comparten un imaginario nacional que tiende a negar el aporte social y cultural de los afrodescendientes, o bien a invisibilizar su presencia, al relegarlos a los remotos tiempos coloniales sin reconocer su existencia contemporánea ${ }^{4}$. Este imaginario se reproduce en el ámbito literario, espacio en el que sobre todo las autorías afrodescendientes suelen ser pasadas por alto ${ }^{5}$. En este sentido, el arribo de estos autores y sus propuestas literarias fueron de entrada contrahegemónicos ${ }^{6}$.

4 Para Centroamérica ver Gudmundson y Wolfe (2012), y para el Caribe ver Martínez (1995).

5 En compilaciones generales como la Historia de los intelectuales en América Latina de Altamirano, es posible observar que los grandes ausentes son los intelectuales afrodescendientes. En el campo literario específicamente, en compilaciones negristas como la de Mansur y González, Poesía negra de América, o la de Salvador Bueno, Cuentos negristas, aunque se incluyen autores afrodescendientes, no hay un análisis sobre estas autorías y sus particularidades.

6 Sobre el impacto de estos autores en el campo literario ver Chacón (2004) y Stinchcomb (2009). 
Aunque Duncan se perfiló como narrador y Jiménez como poeta, ambos exploraron otros soportes literarios a lo largo de sus trayectorias, entre ellos el ensayo, género en el que han desplegado una reflexión autorial sobre la afrodescendencia, la literatura, la escritura y la cultura de sus países. Este trabajo se concentra en dos de ellos: "El escritor afro-hispano y el proceso creativo" (2001), de Jiménez, y "El afrorrealismo. Una dimensión nueva de la literatura latinoamericana" (2005), de Duncan.

El ensayo de Jiménez - que comienza con el tono íntimo de un relato en primera persona- es una reflexión sobre lo problemático que resulta cualquier proceso creativo cuando existe un trasfondo de indefinición colectiva, como la que aqueja a los afrodescendientes de habla hispana. Herederos de una tensión cultural, los afrohispanos se enfrentan a una compleja configuración identitaria en la que confluyen elementos hegemónicos y marginales, y que tiene en la lengua la más evidente expresión de ese conflicto.

A diferencia de otros lugares del continente, en la América Latina de habla hispana no han pervivido lenguas criollas provenientes de la mezcla del español con idiomas africanos, como sí ocurre en zonas de habla francesa, inglesa y holandesa $^{7}$. El español, idioma del colonizador y de la opresión, es la lengua que los afrodescendientes de esta zona han debido adoptar, y si como señaló el intelectual martiniqueño Frantz Fanon, hablar una lengua es cargar con toda una civilización (2009), entonces los afrohispanos han debido asumir una forma de ver e interpretar el mundo que, en buena medida, les fue impuesta. Por ello, según Jiménez:
Al decirnos afro-hispanos, intentamos utilizar el idioma como constante cultural, como la fuerza que une nuestra conciencia colectiva: pero la cul- tura va mucho más allá de la lengua, es la suma total de la versión del uni- verso real que se da un grupo humano [...] Al controlar nuestra definición de cultura, la clase dominante controla nuestra auto-definición y la manera misma de comunicarnos (p.4).

El idioma que se habla, nos dice Jiménez, no es sólo un medio de comunicación, sino una forma de experimentar, entender y relacionarnos con el mundo que nos rodea, y en ese sentido uno de los principales dilemas del escritor afrohispano es cómo hacer frente a una lengua que lo asedia desde distintos flancos. Por un lado, existe una tensión histórica respecto al acceso a la escritura de la lengua del colonizador, celosamente resguardada y no siempre a libre disposición para los

7 La única excepción conocida es el palenquero, lengua que se habla en el Palenque de San Basilio, en las cercanías de Cartagena de Indias, Colombia. Con esto no quiero señalar que no se hablen otros criollos en el territorio de la América Latina hispana, pero su base no está en la mezcla del español con lenguas africanas. Por ejemplo, en casi toda la costa caribeña de Centroamérica se pueden encontrar criollos provenientes del inglés y otros idiomas africanos, los que llegaron con los inmigrantes de las islas del Caribe inglés a fines del siglo XIX (también existen registros de criollos que llegaron con los inmigrantes del Caribe de habla francesa, pero no son predominantes en la zona). 
afrodescendientes. Durante el período colonial y parte del republicano, los africanos y sus descendientes tuvieron acceso al español, principalmente desde la oralidad, pues la escritura estaba reservada para unos pocos, generalmente blancos. De ese privilegio proviene el tan selecto espacio del campo letrado latinoamericano (Rama, 2004) en el que con menos frecuencia de lo deseado encontramos autorías afrohispanas. Además, durante el siglo XX el acceso a la alfabetización en español a través de la educación formal tampoco ha sido fácil para los afrodescendientes: “¿Afro?, ¿Hispano?, ¿Creatividad?, ¿Proceso?, ¿Escritor?... ¿Qué significan estas palabras para mí, para mis hermanos que pueden leer cuartillas de cuarto grado de primaria, o para mis hermanos que no tienen esperanzas de aprender a leer?", se pregunta Jiménez a propósito de estas dificultades. (2001:3)

La relación con la escritura hegemónica tampoco ha sido del todo fluida. Para los escritores afrohispanos resulta complejo desplegar un proceso creativo a través de una lengua que les ha sido impuesta y que muchas veces se muestra reticente a aceptar transformaciones. Según Zapata Olivella (2006), esto es lo que permitiría explicar la falta de propuestas estéticas en el ámbito afrohispano:

La alienación del escritor de ascendencia africana en Latino América se expresa fundamentalmente en el uso de una lengua prestada $[. .$.$] la negredumbre$ del alma africana pura o mezclada en el mestizaje hispano-indígena se queda enmascarada, oculta y casi siempre traicionada. Otro aspecto que ha influido e influye en la obra literaria de nuestros poetas y novelistas afros, es el rígido control que ha ejercido la Real Academia de la Lengua Española a través de sus filiales latinoamericanas, oponiéndose al uso de los nuevos vocablos nacidos en América, tanto de la vivencia de la población afro, zamba o mulata, como de la indígena. En esta forma, el lenguaje de connotación africana se ha reducido al habla coloquial sin trascender al plano estético (Zapata 2006: 171).

Para el intelectual colombiano, la lengua hegemónica aliena al escritor afrodescendiente y oprime su desarrollo creativo cuando mantiene en un lugar inferior "el lenguaje de connotación africana", deslegitimando su potencial estético y su aporte al español. Jiménez, quien coincide con Zapata, sostiene que ante esta situación existen dos opciones: dejar que la cultura pretendidamente universal de lo europeo los absorba, o asumir que no se puede dejar de ser negro en el ámbito hispano y desde ese lugar escribir.

Para el dominicano, sólo esta última posibilidad es la que permitiría a los escritores afrohispanos no paralizarse y dar la batalla. Se trata de una decisión que es consciente del autorreconocimiento que ello implica, es decir, de cargar con una historia de opresión y discriminación de la que muchas veces se quiere escapar y que muchos no quieren ver ni escuchar. Por ello, afirma, es posible perder la voz en el intento; sin embargo, el proceso creativo del afrohispano ya desea "mostrar 
las cadenas" (p.5), y es con esa conciencia para sí que entonces se decide escribir: "Para el escritor afro-hispano el campo decisivo de la lucha es el lenguaje. Hoy tenemos que escoger la lengua dentro de la lengua. Con palabras que nos permitan crear nuestras realidades, hacer el vehículo en el cual vamos a esculpir la pasión que quema las cadenas y libera la mente". (2001: 7)

Esa escritura será en español, pues "la lengua es, al mismo tiempo, vehículo de opresión y liberación” (Jiménez, 2002: 6). Jiménez apuesta a la dimensión liberadora que entrega toda lengua, esa opción que el crítico cubano Roberto Fernández Retamar planteó en los años setenta para pensar el ámbito de lucha del escritor latinoamericano y caribeño de habla hispana, a partir de una reinterpretación descolonizadora del Calibán de Shakespeare (2002) ${ }^{8}$. Para el escritor afrohispano esta perspectiva descolonizadora de la lengua no es simplemente una alternativa, sino un camino ineludible para subvertir el idioma del colonizador y hacer del español una lengua que "sienta, una y otra vez, la desnudez, las soledades, las penas y desesperanzas preñadas de futuros. Re-crearnos en ser afro-dominicanos, afro-cubanos, afro-colombianos, afro-panameños, afro-americanos" (Jiménez, 2002: 7). Por eso, conmina Jiménez, "tenemos que cambiar la lengua, transformándola con nuestra visión afro-céntrica" (2002: 6).

El escritor dominicano, si bien no señala cómo se debe seguir por ese camino transformador, tal vez para dejar abiertas las múltiples opciones que existen, revela una tensión que aun a comienzos del siglo XXI está presente y no del todo resuelta, y en ese sentido la potencialidad de su ensayo radica en la necesidad de mantener activa esta discusión.

Cuando en el 2005 Duncan propone el afrorrealismo como una forma de producción estética, da cuenta de buena parte de las preocupaciones expuestas por Jiménez, pero decide dar un paso más allá y construye un verdadero manifiesto de la creación literaria afrohispana. Aunque el término lo acuña casi una década antes (Duncan, 1996), es en este ensayo donde expone y discute la posibilidad de comprender como una corriente literaria las producciones de autorías afrodescendientes que hacen una subversión africanizante del español. Así, su propuesta define el afrorrealismo como:

Una nueva corriente literaria latinoamericana, cuya poética se aparta en algunos aspectos de los referentes tradicionales de la literatura del "main stream" [...] Se distingue claramente con relación al negrismo y de la negritude, y aunque comparte algunos rasgos, se distingue también del realismo mágico por sus símbolos, mitos y por su perspectiva. El afrorrealismo es una nueva expresión de las literaturas hispánicas $(2005, \mathrm{~s} / \mathrm{p})$.

8 Esta perspectiva la inaugura el barbadense George Lamming en su texto Los placeres del exilio, publicado en 1960, en el que metaforiza el colonialismo y sus consecuencias a través del análisis del personaje de Calibán, de la obra teatral La tempestad de William Shakespeare. 
Para diferenciarla de otras perspectivas literarias, entrega seis aspectos que delinean esta corriente: 1) la voz afro-americana; 2) la memoria simbólica africana; 3) la memoria histórica de la diáspora africana; 4) la reafirmación de una comunidad ancestral; 5) perspectiva intra céntrica; 6) la identidad afro. Duncan se explaya en cada uno de estos aspectos con el objetivo de comprenderlos bajo un determinado contexto histórico. Para el autor no sólo se trata de incorporar estos elementos en la escritura, sino hacer de ellos un uso con sentido, pues como enfatiza:

La recurrencia a la subversión africanizante del idioma, los referentes míticos inéditos o hasta ahora marginales, tales como el Muntu, el Samanfo, el Ebeyiye, la reivindicación de las deidades como Yemayá, y la incorporación de elementos del habla popular de la diáspora africana son factores medulares y no decorativos en la obra de estos autores (Duncan, 2005, s/p).

Lo anterior supone que el afrorrealismo no siga pautas literarias ni hispánicas ni africanas, y que los escritores afrohispanos que lo impulsan hagan de la lengua una herramienta que dé cuenta de esa experiencia mestizada de la cual los afrodescendientes son herederos; por ello, para Duncan "el lenguaje no es africano ni hispánico. Es afroamericano (Duncan, 2013: 7).

El mestizaje, en tanto proceso sociocultural, es un aspecto relevante para comprender la propuesta de Duncan ${ }^{9}$. El afrorrealismo no debe entenderse como un enfoque encerrado en sí mismo, pues aun cuando asume una perspectiva afrocéntrica que exalta las herencias culturales africanas, reconoce un horizonte histórico de múltiples influencias culturales. Para el autor:

La búsqueda de la identidad que caracteriza a los autores afrorrealistas desafía la falsa dicotomía blanco-negro para recuperar una parte negada de su identidad como afrodescendiente. En el proceso, ese reclamo admite todas las variables de mestizaje, incluyendo el aporte europeo. $\mathrm{Y}$ en abierta renuncia de toda posición etnofóbica, los afrorrealistas asumen su condición de africano, latino e indígena, sin dejar de lado los aportes de otras etnias" (Duncan, 2005, s/p).

9 Duncan, en este sentido, establece un diálogo con las propuestas de Guillén y sobre todo con las de Zapata Olivella sobre la necesidad de pensar al sujeto negro o afrodescendiente en la América de habla hispana, no sólo en relación al blanco/europeo, sino también al indígena y a los múltiples mestizos en el marco de las fronteras nacionales. Tanto Guillén como Zapata sostienen que la especificidad del negro o afrodescendiente en la zona pasa por estos múltiples vínculos El poeta cubano, en su conocido prólogo de 1931, termina señalando: "Por lo pronto, el espíritu de Cuba es mestizo. Y del espíritu hacia la piel nos vendrá el color definitivo. Algún día se dirá "color cubano"' (2002, p.100). Zapata, por su parte, en la Introducción a su libro ;Levántate mulato!, en el que reflexiona sobre el mestizaje, plantea: “¿Híbrido o hombre nuevo? ¿Soy realmente un traidor a mi raza? ¿Un zambo escurridizo? ¿Un mulato entreguista? O sencillamente un mestizo americano que busca defender la identidad de sus sangres oprimidas" (1990, p. 21). Duncan lleva estas consideraciones al campo literario, en cuyo espacio creativo se reproducen las tensiones de estos procesos histórico-sociales. 
Es por ello que en Duncan hay una mirada dinámica de la lengua; esta debe expresar la realidad a la que se vincula y, por tanto, ir variando y aceptando nuevos elementos en la medida que dicha realidad se modifica, pero esa posibilidad ha sido negada para los creadores afrohispanos. La introducción de elementos de la oralidad en las producciones escritas ha sido siempre un acto de sospechosa erudición, inadmisible para el campo letrado latinoamericano, pero recurrente en la producción literaria afrohispana. De este modo, la apuesta del afrorrealismo también pasa por dar cabida a esa forma de organizar la realidad que entrega la oralidad y que permitiría "restituir a la comunidad afrodescendiente su propia voz", tal como lo expresa el autor: "No se trata de una voz inventada, de un discurso elaborado para la ocasión. Y ni siquiera es un manifiesto explícito. Esa voz tiene su asiento en la oralidad afroamericana a cuyo conjuro va al rescate. Se trata de la dignificación de la palabra diaspórica de las comunidades negras" (Duncan, 2013: 5).

El afrorrealismo debe comprenderse no sólo como una propuesta para la creación literaria, sino además como una forma distinta de aproximarse a una producción literaria ya existente. Es cierto que Duncan lo define como una nueva corriente, pero ello debe entenderse ante la demanda por abrir el canon latinoamericano a otras tendencias e incorporarlas al campo literario. Para el intelectual costarricense, el afrorrealismo se inaugura con Nicolás Guillén y sus Motivos de son a comienzos del siglo $\mathrm{XX}^{10}$, y desde entonces ya es posible rastrear una literatura afrohispana, tal como Smart lo señaló en 1984 para el caso centroamericano. Pero esto sólo será posible con un cambio de enfoque que vuelva a mirar, ahora con otros ojos, las producciones escritas de autorías afrohispanas, tarea que parece estar aún pendiente.

Los dos ensayos a los que aquí se ha hecho referencia coinciden en la figura del escritor afrohispano y en la lengua como el eje en torno al cual giran sus dilemas creativos. Se trata de una figura poco investigada que pone en el tapete una herencia colonial muchas veces pasada por alto en las zonas hispanas de América Latina. Por ello debe llamar nuestra atención el que sean autores afrodescendientes quienes la trabajen. El afrorrealismo de Duncan no es simplemente una propuesta

10 Respecto a Guillén, Duncan detalla: "Él no fue el introductor del tema afro en la literatura latinoamericana. Ya los autores negristas se habían encargado de hacerlo. Tampoco fue el primer escritor afrodescendiente en América Latina, pues antes que él, por citar dos casos, publicaron Juan Francisco Manzano (1797-1854) sus Cantos a Lesbia en 1821 y sus Flores pasajeras en 1830; y el afrocolombiano Candelario Obeso, en 1874 publicaba poemas en los periódicos y en 1877, su poemario Cantos populares de mi tierra. Más, la obra de Nicolás Guillén iba a marcar una diferencia sustancial, una nueva corriente de pensamiento literario, dando a lo afro un inédito sentido de pertenencia [...] Presentes en sus escritos están experiencia y combates de la africanía en sus territorios natales, en los barcos negreros, en los cimarronajes que lograron establecer en Las Américas, en sus luchas por la libertad primero y contra la invisibilización, la marginación y la exclusión de los ámbitos del poder. Y presenta sus conocimientos en exposiciones lógicas y en arte. Es un pensar nuevo, una estética cumbre, definitivamente castellana y singularmente afro, articulada y completa, una visión intelectual acorde con los nuevos tiempos (2013, p.5). 
estética, así como tampoco las reflexiones de Jiménez versan sobre una experiencia autorreferente; ambas son expresiones resultantes de intelectuales que hacen de la escritura un acto consciente de autorreconocimiento, en el que a las preguntas por qué y cómo escribir se agrega el desde dónde hacerlo. El lugar de enunciación del escritor afrohispano, ese espacio en el que se reconoce afrodescendiente, se transforma en un aspecto clave para comprender a esta figura intelectual, cuya presencia trasciende el ámbito literario para ubicarse en la disputa social y política por el derecho a su identidad.

\section{Referencias}

Andrews, George Reid. (2007). Afro-Latinoamérica, 1800-2000. Madrid: Iberoamericana Vervuert. (Trabajo original publicado en 2003).

Chacón, Albino. (2004). "El sentido de la literatura de Quince Duncan en la historia cultural de Costa Rica, a propósito de la publicación de sus Cuentos escogidos". Disertación presentada en el Museo Nacional de Costa Rica.

Duncan, Quince. (2013). "El afrorrealismo en Nicolás Guillén y Jorge Artel". Revista Comunicación, 22 (1), 4-11.

. (2005). "El Afrorrealismo. Una dimensión nueva de la literatura latinoamericana". Revista Istmo. Recuperado de http://istmo.denison.edu/n10/articulos/afrorealismo.html

. (1996). Un señor de chocolate. Treinta relatos de la vida de Quince. Heredia, Costa Rica: Universidad Nacional.

Fanon, Frantz. (2009). Piel negra, máscaras blancas. Madrid: Akal. (Trabajo original publicado en 1952).

Fernández Retamar, Roberto. (2002). Todo Calibán. Puerto Rico: Ediciones Callejón.

Guillén, Nicolás. (2002). Donde nacen las aguas. Antología. México: FCE.

Gudmundson, Lowell \& Wolf, Justin (Ed.). (2012). La negritud en Centroamérica. Entre raza y raices. San José, C. R.: EUNED.

Mullen, Edward. (1988). The Emergence of Afro-Hispanic Poetry: Some Notes on Canon Formation. Hispanic Review, 56 (4), 435-453.

Jackson, Richard. (1991). The Emergence of Afro-Hispanic Literature. Afro-Hispanic Review, 10(3), 4-10.

. (1988). Afro-Hispanic Literature: Recent Trends in Criticism. Afro-Hispanic Review, 7 (1/2/3), 32-35. 
. (1979). Black Writers in Latin America. USA: University of New Mexico Press.

Jiménez, Blas. (2002). El escritor afro-hispano y el proceso creativo. Afro-Hispanic Review, 21 (1/2), 3-8.

Martínez Montiel, Luz María (coord.). (1995). Presencia africana en el Caribe. México: Consejo Nacional para la Cultura y las Artes.

Rama, Ángel. (2004). La ciudad letrada. (1ª Ed. 1984). Santiago de Chile: Tajamar Editores.

Stinchcomb, Dawn. (2009). Negritud literaria en la República Dominicana. Quito: Ediciones Abya-Yala. (Trabajo original publicado en 2004).

Wilson, Carlos Guillermo. (1991). The Role of the Afro-Latino Writer and the Quincentenary (1492-1992). Afro-Hispanic Review, 10 (3), 67-71.

Zapata Olivella, Manuel. (2006). Los problemas de identidad de los escritores afro-latinoamericanos. Afro-Hispanic Review, 25 (1), 171-173. bia: Rei.

(1990). ¡Levántate mulato! Por mi raza hablará el espíritu. Colom- 